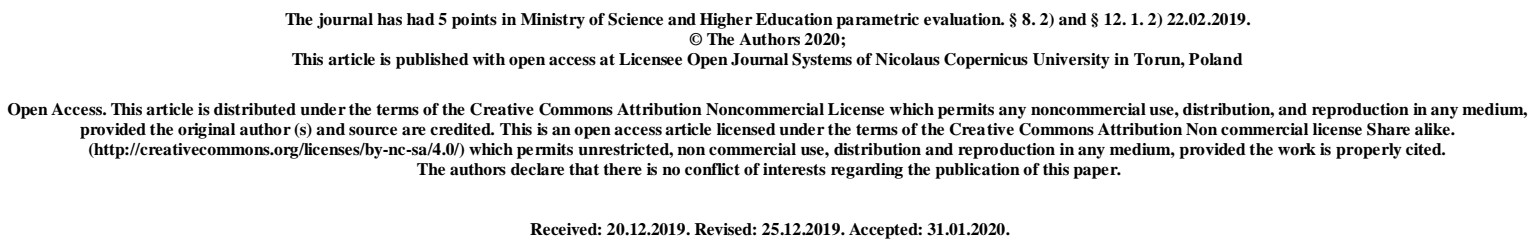

\title{
THE PECULIARITIES OF MEDICAL CARE ORGANIZING FOR PATIENTS WITH VIRAL HEPATITIS IN UKRAINE
}

Vasyl Mykolayovych Mykhalchuk, Doctor of Medicine, Professor, Head of the Health Care Management Department, NMAPE named after P L Shupik;

Valeriy Anatoliyovych Pishchikov, Doctor of Medicine, Professor, Chief Researcher of the Scientific Department of Medical Care Organization, Deputy Head of the Department of

\section{Health Care and Sanatoriums of the State Administration}

\section{Abstract}

The problem of chronic viral hepatitis is gaining relevance. Many authors consider the issues of epidemiology as well as medical and diagnostic problems. Revising the structure of health care facilities (HCFs), a lack of specialized medical care units was defined.

The purpose of the Program is to ensure access of the general population to the prevention, diagnosis and treatment of viral hepatitis B and C in Ukraine in order to stabilize the epidemic situation, reduce morbidity, disability and mortality, increase the duration and quality of patients life.

\section{Keywords: hepatitis B and C; epidemiology; revention; diagnosis; treatment}

Actuality. The problem of chronic viral hepatitis is gaining relevance. Many authors consider the issues of epidemiology [1, 2] as well as medical and diagnostic problems [3, 4]. At the same time, the problem of medical care organizing for such patients is poorly covered and professionally developed. As a confirmation, it should be noted that the main government programs began their work in the early 2010s [5, 6]. Revising the structure of health care 
facilities (HCFs), a lack of specialized medical care units was defined. Analytical data related to organizational work began to be systematically collected and monitored relatively recently, namely after the formation of specialized hepatocenters. The problem is only gaining relevance taking into account the numerous reforms in Ukraine aimed at changing the funding of the medical sector and its structure.

The purpose of the work is to demonstrate the peculiarities of the structure of the medical care organizing for patients with viral hepatitis in Ukraine.

Materials and methods. The regulatory framework which is used in Ukraine and related to medical services for patients with viral hepatitis was analyzed - legislation, regulations and orders of executive authorities in Ukraine at various levels. The analysis used official resources that posted information on this section of medicine.

Results. Viral hepatitis is a group of socially significant infections with a relatively long prodromal period. As already proven the role of viral agents in the occurrence of the disease, it makes its adjustments in the organizing of health care in general. The approach to diagnosis and treatment will be changed due to investigation and further detailed description of the pathogens. This should also affect the principles of medical care organizing in general.

When defining an organizational model, many countries choose the one that is most susceptible to early diagnosis as well as early treatment. The reason for this is that viral hepatitis belongs to the group of socially significant diseases and affects the main public health indicators.

Many authors in clinical studies have proven the similarity of epidemic process of chronic viral hepatitis with other viral diseases. However, there are certain peculiarities of the epidemic process. These features are observed from the moment the patients are infected.

The network of HCFs related to medical counseling is to be developed taking into account the issues mentioned above [7]. It is the factor that will help prevent infections by raising awareness.

Another feature is the pathogenesis of the disease. It is characterized by a long prodromal period, which affects the conditions of early diagnosis. This causes a relatively low turnout of such patients in the early stages of the disease. In the context of the formation of family medicine, it is extremely difficult for a general practitioner to diagnose chronic viral hepatitis. Specific tests are not included in the mandatory state-compensated diagnostic program. 
In most cases, the disease is diagnosed at the stages of already persistent dystrophic and fibrous changes in the liver. in such cases the medical care is aimed usually at combating the disease or treating complications arising from chronic liver failure.

These factors affect the structure of medical institutions. In most cases they means an inpatient intensive care. These types of care are more expensive in the overall program than outpatient treatment.

If a patient has oncological liver pathology or decompensated liver insufficiency, there is a need for additional significant funding aimed patients recovery.

Given the fact that the prevalence and incidence of chronic viral hepatitis are increasing every year, in Ukraine a new system of HCFs should be developed and implemented on an outpatient basis, rather than inpatient.

The developing medical care structure is based on international guidelines. This method is chosen to take into account the widest range of specialists mentions in various fields from different countries. At this level, it becomes possible to identify specific recommendations for numerous scientific studies.

Taking into account a significant number of studies in hematology and virology as well as in related scientific fields, the WHO annually issues recommendations for all stages of medical care [8]. Specialists in the field of medical care structures development are analyzed a large number of reliable studies, on the basis of which it becomes possible to calculate all the options for assistance.

Sufficient number of recommendations is available from published data of professional academies, institutions, etc., which also provide information of a recommendatory nature, as well as information related to HCFs organizing [9].

No less important factor in HCFs`organizing have the current stages of the health care system in Ukraine reform [10]. The main priorities of the reform are relying on the economic model of the system.

In recent years in Ukraine as in most other countries the special attention has been paid to the sources of funding for the health care system. The idea of HCFs financing from various sources was arised after the collapse of the Soviet Union, in which was dominated the system proposed by M.O. Semashko [11]. In this system the following priorities were declared as a basis:

free of charge general medical care was guaranteed by the state at the legislative level; 
- $\quad$ the health sector was managed by the Ministry of Health, and all HCFs were governmental;

- $\quad$ there were two dominant principles: territorial and hierarchical;

- $\quad$ the medicine in general was preventive mainly.

The above ideas remained declarative and mostly on paper, and the volume as well as the quality of medical care for ordinary citizens needed to be better. In real life, the problem of viral hepatitis was not among the priorities and those to which the state paid special attention.

Given that the HCFs are fully funded by the state through its regulatory bodies, it had the opportunity to influence on development policies of these institutions. Namely, according to the decisions of state bodies, institutions that were engaged in general medical practice were defined. The task of these institutions was to identify and treat the most common diseases. Institutions that specialized in certain nosological forms were concentrated at all stages of disease treatment. For example, a wide network of dispensaries was created: oncology, tuberculosis, dermatovenereology and others. With the functioning of this system it would be logical to create a separate institution, which would deal with the problems of viral hepatitis. However, the problem was considered only as a manifestation of acute hepatitis, patients were referred to infectious departments, and in the event of acute complications - in surgical hospitals often.

The dominant position in the structure of the disease in the twentieth century was placed by viral hepatitis A, the pathogenesis and epidemiology of which differed from those of chronic viral diseases. And if chronic forms were detected, they were transferred to the category of disease due to cirrhosis or carcinoma and referred to specialized HCFs.

Over the years, the problem has not lost its actuality. This is provoked primarily by changes in the structure of morbidity, transformations of recent decades in social and economic systems, advances in medicine. This is due to the fact that modern opportunities highlight on the true pathomorphological and pathophysiological features of liver disease. As an example, chronic forms of hepatitis are increasingly being diagnosed. Of course, there is a need to create a modern diagnostic and treatment base, following re-profiling of the HCFs.

By the relevant structures of the international level is set the dynamics in the form of providing recommendations for treatment and appeals to international funds to combat viral hepatitis [12-15].

An example of the problem is the lack of a national program to combat chronic viral hepatitis. The last such program "State targeted social program for prevention, diagnosis and 
treatment of viral hepatitis for the period up to 2016" was adopted in 2013 and approved by the Cabinet of Ministers of Ukraine dated April 29, 2013 № 637 [5]. This document regulates all relationships regarding the medical aspects of chronic viral hepatitis.

The purpose of the Program is to ensure access of the general population to the prevention, diagnosis and treatment of viral hepatitis B and C in Ukraine in order to stabilize the epidemic situation, reduce morbidity, disability and mortality, increase the duration and quality of patients life.

This program was designed to create specialized hepatocenters under the regional subordination. For the first time, an attempt was made at the level of the Cabinet of Ministers of Ukraine to specify the problem and present clear tasks on various aspects. These aspects are organizational, preventive and diagnostic-therapeutic, namely [5]:

\section{Organizational:}

1. To make changes into existed and develop new regulations and medical as well as technological documents related to prevention, diagnosis and treatment of viral hepatitis B and $\mathrm{C}$.

2. To improve the mechanism of providing medical care to patients with viral hepatitis $\mathrm{B}$ and $\mathrm{C}$ in the context of reforming the health care system by improving its quality.

3. To provide scientific support to the Program.

4. To strengthen the interaction of executive bodies with public associations and international organizations working to counteract the spread of viral hepatitis B and C.

5. To improve the registration system for patients with viral hepatitis B and C.

6. To ensure improvement of the material and technical base of health care facilities that diagnose and treat viral hepatitis B and C.

\section{Preventive:}

1. To ensure the implementation of large-scale informational and educational activities in terms of the viral hepatitis B and C prevention.

2. To increase the level of the blood donation safety in order to prevent the transmission of viral hepatitis B and C.

3. To ensure compliance with infection control requirements in HCFs and consumer services.

4. To ensure vaccination against viral hepatitis B at key groups population.

\section{Diagnostic and therapeutic:}

1. To ensure access of wide population to the diagnosis of viral hepatitis $B$ and $C$ using modern methods. 
2. To provide access to modern methods of treatment of viral hepatitis $B$ and $C$ for patients who need it.

3. To ensure clinical and laboratory monitoring of treatment effectiveness through patients with viral hepatitis B and C.

4. To ensure internal and external quality control of laboratory tests for viral hepatitis $\mathrm{B}$ and $\mathrm{C}$.

Some positive results were achieved during the Program:

1. Development of the health care system in the field of care for patients with viral hepatitis B and C.

2. Improving the mechanism of medical and social care for patients with viral hepatitis $\mathrm{B}$ and $\mathrm{C}$ in terms of reforming the health care system, ensuring the development of specialized medical care and access of the general population to the diagnosis and treatment of viruses hepatitis.

3. Ensuring infectious safety of donor blood and its components.

4. Providing treatment and prevention for patients with viral hepatitis B and C.

5. Providing scientific support to the Program.

6. Increasing the level of information support.

7. Ensuring compliance with the requirements of infection control in the HCFs and at household service enterprises.

8. Improving the system of medical workers training under the "infectious diseases" specialty.

9. Establishing an international cooperation on prevention and provision of medical care to patients with viral hepatitis B and C.

It should be noted that each indicator was divided into several sub-items, which makes it possible to more thoroughly assess the situation on this issue and plan actions in response.

Thus, the state bodies clearly defined the tasks until 2016. The program is not currently extended.

Although many local health administrations have independently made proposals for the organization of health care, the main theses for development of regional programs were taken from the Program. Control and responsibility fell on the shoulders of the heads of structural units for health care of regional and city state administrations. This may have been influenced by national factors in governance. Thus began the decentralization and reform of health care. 
The last reform began after adoption of the Law of Ukraine of October 19, 2017 № 2168-VIII "On state financial guarantees of medical care" [16]. This has had a negative impact on epidemiological indicators related to chronic viral hepatitis. The optimization of the health care sector, in particular the facilities that provide highly specialized medical care, has led to a number of significant changes. At the same time, in contrast to patients' satisfaction with the primary care reform, at the third level there was no reorientation to prevention and emphasis on medical care itself. Although the ideas for reforming secondary and highly specialized care were not implemented by predecessors.

Numerous local reform attempts, with approval of oblast and rayon councils, have also made adjustments to formation of specialized HCFs. One of the negative factors was merging of health departments of the state administrations with other departments of regional and district authorities, and field attempts were explained by ways of optimization.

The reduction of staff number of infectious diseases departments and specialized centers was a negative factor for the mentioned specialized HCFs.

In fact, the situation regarding organizingn of medical care for patients with chronic viral hepatitis has not changed for the better. In 2016, the WHO proposed the "Progress report on HIV, viral hepatitis and sexually transmitted infections, 2019Accountability for the global health sector strategies, 2016-2021" [17].

This strategy has a recommendatory nature in the fight against chronic viral hepatitis. Each country develops its own strategy for studying the problem and implementing measures on the ground. In Ukraine, the Ministry of Health has assigned a function to the Center for Public Health of the Ministry of Health of Ukraine. This Center has absorbed all the functions of regulating public policy. Efforts have been made to combat not only chronic viral hepatitis, but also HIV/AIDS and tuberculosis. Virtually all administrative and medical-diagnostic recommendations are implemented by this center. We should not forget about the establishment of the National Health Service of Ukraine (NHSU). Because this organization first of all took over the financing of practical medicine in Ukraine. The main indicators of its work are the number of services provided to the population. This can affect the quality of care for such patients.

There are several factors influencing the situation. Firstly, in the early stages, all patients need mostly outpatient care, which will reduce the number of consultations for such patients. Secondly, even small invasive methods of diagnosis and treatment will only worsen the situation because they require additional resources compared to patients without chronic 
viral hepatitis. This fact can lead to the refusal of medical care by HCFs staff. Thirdly, the target programs of the NHSU do not clearly provide for the creation and maintenance of specialized institutions in general. This problem is becoming more acute in terms of funding. The programs that exist today do not provide sufficient costs for highly specialized care. For example, the purchase of diagnostic tests for viral hepatitis is partly entrusted to local budgets.

At the local level the situation remains stable. On the contrary, each region can form its own program. This phenomenon arose after decentralization of the territory and HCfs. If local communities or individual HCFs see the prospect of developing medical care for viral chronic hepatitis, funding will increase.

In practice, there is a situation when local authorities begin to take into account the main indicators of mortality and morbidity on the ground. Funds are allocated mainly to programs to combat acute coronary syndrome and stroke programs. This can lead to an increase in morbidity, disability and mortality among patients with viral hepatitis. There is also a certain risk of increased co-payment for diagnosis and treatment due to this cohort of patients with hepatitis.

Conclusions: Analyzing the situation regarding organization of HCFs to combat chronic viral hepatitis, we came to the following conclusions:

1. The main information and methodological framework for development of the HCFs is international and is presented in the form of recommendations by the WHO, the American Association for the Study of Liver Diseases, the Centers for Disease Control and Prevention and others.

2. Due to the various reforms in Ukraine the structures of HCFs in the regions will differ significantly in the nearest future.

3. Not only epidemic and pathophysiological factors, but also administrative policy plays an important role in forming the structure of these institutions.

\section{References}

1. European Association for the Study of the Liver. EASL recommendations on treatment of hepatitis C 2016. J Hepatol. 2017 Jan; 66 (1) : 153-94.

2. Alonso M., Gutzman A., Mazin R. et al. Hepatitis C in key populations in Latin America and the Caribbean: systematic review and meta-analysis. Int J Public Health. 2015; $60(7)$ : 789-98. 
3. Cuomo G, Borghi V, Giuberti T, Andreone P et al. What to start with in first line treatment of chronic hepatitis B patients: an Italian multicentre observational cohort, HBVRER study group // Infez Med. 2017 Jun 1; 25(2):150-157.

4. University of Liverpool. Hepatitis drug interactions [Internet]. HEP Drug Interactions. 2017. Available from: http://www.hep-druginteractions.org/.

5. Resolution of the Cabinet of Ministers of Ukraine dated 29.04.2013 № 637 “On approval of the State target social program for prevention, diagnosis and treatment of viral hepatitis for the period up to 2016." URL https://zakon.rada.gov.ua/laws/show/637-2013p\#Text (accessed 25.01.2020).

6. Order of the Cabinet of Ministers of Ukraine of March 9, 2011 № 206-r “On approval of the Concept of the State targeted social program for prevention, diagnosis and treatment of viral hepatitis for the period up to 2016." URL https://zakon.rada.gov.ua/laws/show/206-2011-p\#Text (Access date 22.01.2020).

7. Kravchenko V.V., Orlova N.M. Ways to increase public satisfaction with the quality of outpatient care // Ukraine. Health of the nation. - 2018. - № 2. - P. 38-42. - Access mode: http://nbuv.gov.ua/UJRN/Uzn_2018_2_10 (Access date 12.12.2019).

8. WHO Global Hepatitis Progamme. Prevention and control of viral hepatitis infection: interim strategy for global action 2016-2021. Geneva, World Health Organization. 2016. P. 56.

9. Unified clinical protocol of primary, secondary (specialized), tertiary (highly specialized) medical care: viral hepatitis $\mathrm{C}$ in adults. - Officer. kind. - Kyiv: Ministry of Health of Ukraine, 2016. - 39 p. - (Appendix to the order of the Ministry of Health of Ukraine № 729 dated 18.07.2016).

10. National strategy for reforming the health care system in Ukraine for the period 2015-2020. URL: https://moz.gov.ua/uploads/0/691-strategiya.pdf (accessed 28.01.2020).

11. Baeva O.V. Healthcare Management. Teaching. manual. - Kyiv: Center for Educational Literature, 2008. - 640 p.

12. European Association for Study of Liver, Asociacion Latinoamericana para el Estudio del Higado. EASL-ALEH Clinical Practice Guidelines: Non-invasive tests for evaluation of liver disease severity and prognosis. J Hepatol. 2015 Jul;63 (1) : 237-64.

13. Centers for Disease Control and Prevention. Viral hepatitis surveillance - United States, 2009 [Internet]. Available from: https://www.cdc.gov/hepatitis/Statistics/2009Surveillance/Commentary.htm 
14. AASLD/IDSA HCV Guidance Panel. Recommendations for testing, managing, and treating hepatitis $\mathrm{C}$ [Internet]. American Association for the Study of Liver Diseases (AASLD); 2017. Available from: http://www.hcvguidelines.org/full-report-view.

15. Fraser K., Perez R., Latour C. (eds.) CMSA's Integrated Case Management: A Manual for Case Managers by Case Managers. Springer Publishing Company, 2018. - 316 p.

16. Law of Ukraine "On state financial guarantees of medical care". Information of the Verkhovna Rada, 2018, № 5, p.31.

17. Progress report on HIV, viral hepatitis and sexually transmitted infections 2019. Accountability for the global health sector strategies, 2016-2021. WHO. Geneve. 2019.-P. 48. 